\title{
BENTUK PENYAJIAN TARI LUKAH GILO DI MASYARAKAT SIJUNJUNG, SUMATERA BARAT
}

\author{
Oleh: \\ Devi Kurnia Santi \\ Jurusan Tari Fakultas Seni Pertunjukan, Institut Seni Indonesia Yogyakarta \\ Alamat email : devikurnias92@gmail.com
}

Tari Lukah Gilo merupakan salah satu kesenian yang hidup dan berkembang di Sijunjung, Sumatera Barat yang syarat dengan kekuatan supranatural dan unsur magis. Tari ini menggunakan lukah (bubu) sebagai properti utamanya. Pada dasarnya, tarian ini berupa kontrol atau pengendalian lukah (bubu). Keunikan pada tarian ini terletak pada properti lukah yang dapat menari dan bergerak sendiri setelah dibacakan mantera oleh kulipah, sehingga lukah tersebut akan melompat dan juga menari tanpa digerakkan oleh seseorang.

Masalah dalam penelitian ini adalah bentuk penyajian tari Lukah Gilo di masyarakat Sijunjung, Sumatera Barat. Dalam membedah masalah yang ada, penelitian ini menggunakan metode deskripsi analisis dengan menggunakan pendekatan antropologi sebagai konteks dalam melihat keberadaan tari Lukah Gilo, yang dipengaruhi oleh aspek sosial, budaya, sejarah, latar belakang dan masyarakat pendukungnya. Untuk membedah bentuk penyajian tari dengan melihat analisis bentuk penyajian tari Lukah Gilo melihat tiga tahap proses pertunjukan, yaitu (1) proses persiapan yang meliputi mempersiapkan lukah, lukah direndam, lukah dipakaikan baju dan dirias, (2) pelaksanaan atau pementasan dipimpin oleh kulipah dengan menghadirkan jin untuk meng-gilo-kan lukah, (3) penutup untuk mengembalikan para jin ke tempat semula saat dipanggil.

Berdasarkan hasil yang diperoleh, penyajian tari Lukah Gilo menarik dikarenakan tarian ini tidak hanya berfungsi sebagai hiburan, akan tetapi juga untuk menguji ketangkasan dari anak-anak muda dan masyarakat Minang dalam mengontrol lukah yang sudah diberi mantera. Bentuk penyajian juga telah mengalami banyak perkembangan, terlihat pada penggunaan kostum dan alat musik sebagai iringannya. Meskipun bertentangan dengan agama Islam, namun tari Lukah Gilo tetap berada pada undang-undang adat, yaitu adat nan diadatkan sebagai warisan nenek moyang, dan tidak bertentangan dengan falsafah adat Minangkabau "Adat basandi syarak, syarak basandi kitabullah”.

Kata kunci: Lukah Gilo, Bentuk Penyajian, Sijunjung 


\begin{abstract}
Lukah Gilo dance is one of the arts that is alive and thriving in the Sijunjung, West Sumatera that terms with supernatural powers and magical elements. This dance used lukah (bubu) as its main property. Basically, this dance form's the control of lukah (bubu). The uniqueness of this dance lies in lukah's property who's can dance or moves on its own after the spell was recited by kulipah.

The problem in this research is a presentation form of Lukah Gilo dance in Sijunjung society, West Sumatera. In dissecting the problem, this research using the method of the description of the analysis with the use of anthropology approach as context in view of the existence of the Lukah Gilo dance which is influenced by social, cultural, history, background, and community supporters. To dissect the form of the presentation of dance by looking at the analysis of the presentation form of Lukah Gilo dance sees three stages of the show process, (1) the preparatory process which includes preparing lukah, soaked the lukah, lukah wearing costume and applied makeup, (2) the implementation or performance is led by kulipah for presenting jin, (3) cover to restore the jin to the original place when called.

Based on the results obtained, presenting of Lukah Gilo dance are interesting, because the dance is not only serves as an entertainment, but also to test the agility of young kids and Minang's society in controlling lukah already given a mantra. The presentation form also has undergone many developments, looks at the use of costume and musical instruments as accompaniment. Although contrary to Islam religion, but Lukah gilo dance remains on customary law, there is adat nan diadatkan as the inheritance of the ancestors, and doesn't conflict with the Minangkabau philosophy "adat basandi syarak, syarak basandi kitabullah".
\end{abstract}

Keywords: Lukah Gilo, Form, Sijunjung. 


\section{PENDAHULUAN}

Sumatera Barat secara kultural dikenal dengan sebutan Minangkabau. Minangkabau merupakan salah satu daerah budaya di Indonesia yang didiami oleh masyarakat yang dikenal dengan suku bangsa (etnis) Minangkabau (Tsuyoshi Koto, 1983: xi). Prinsip adat Minangkabau tertuang singkat dalam pernyataan Adat basandi syarak, syarak basandi Kitabullah (Adat bersendikan agama, agama bersendikan kitabullah, kitab Allah atau Al Qur'an) yang berarti adat berlandaskan ajaran Islam. Nama Minangkabau berasal dari dua kata, Minang dan Kabau. Nama itu dikaitkan dengan suatu legenda Minang yang dikenal di dalam tambo, yang menceritakan bahwa nenek moyang mereka berasal dari keturunan Iskandar Zulkarnain. Awalnya penyebutan orang Minang belum dibedakan dengan orang Melayu, namun sejak abad ke19, penyebutan Minang dan Melayu mulai dibedakan melihat budaya matrilineal yang tetap bertahan berbanding patrilineal yang dianut oleh masyarakat Melayu umumnya, kemudian pengelompokkan ini terus berlangsung demi kepentingan sensus penduduk maupun politik.

Wilayah budaya Minangkabau secara tradisional terbagi menjadi dua, yaitu dataran tinggi disebut daerah darek dan dataran rendah disebut daerah pasisia atau rantau. Setiap luhak mempunyai daerah rantau yang bersebelahan dengan daerah luhak (Muchtar Naim, 1984: 14). Setiap wilayah tersebut masing-masing memiliki keaneka-ragaman jenis kesenian tradisional, salah satunya adalah kesenian tradisional yang berada di masyarakat Sijunjung.

Kehidupan masyarakat Sijunjung kental dengan adat istiadat Minangkabau dan tetap berusaha untuk menjaga dan melestarikan kebudayaannya yang telah ada sejak dahulu, terutama seni tari sebagai bagian integral dari spirit komunal. Seperti dikemukakan oleh Soedarsono, bahwa salah satu bentuk kesenian yang tumbuh dan berkembang dalam kehidupan manusia adalah tari (R.M Soedarsono, 1997: 17). Tari dalam budaya atau masyarakat tertentu merupakan realisasi atau perwujudan dari ekspresi kehidupan masyarakat. Bentuk dan sifat serta ciri dalam tari biasanya disebabkan oleh banyak hal seperti: lingkungan, sejarah masyarakat, dan juga kebiasaan masyarakat setempat. Tari tercipta sebagai bentuk ekspresi manusia yang diungkapkan melalui gerak berdasarkan keinginanya yang bertujuan sebagai pemenuhan kebutuhan akan naluri mengenai hiburan atau keindahan.

Tari Lukah Gilo merupakan salah satu tarian yang syarat dengan kekuatan supranatural atau magis. Tari ini menggunakan lukah (bubu) sebagai properti utamanya. Istilah lukah gilo berasal dari dua kata, yaitu lukah (bubu) yaitu alat penangkap ikan atau belut berbentuk lonjong terbuat dari anyaman lidi atau rotan, sementara gilo adalah bahasa Minang untuk kata "gila". Arti gilo pada tarian ini yaitu lukah yang dapat bergerak ke manamana dan gerakannya tak terkendali setelah lukah tersebut dibacakan mantra oleh kulipah. Keunikan yang terletak pada tarian ini adalah penggunaan properti lukah yang dapat menari dan bergerak sendiri setelah dibacakan mantra oleh kulipah, sehingga lukah tersebut akan melompat dan juga menari tanpa digerakkan oleh seseorang. Pergerakan dari lukah tersebut biasanya sesuai dengan mantra yang diberikan sang kulipah. Tarian ini terinspirasi dari cerita Duhak, seorang warga Sijunjung yang gemar 
mencari ikan di sungai menggunakan lukah (bubu), yaitu alat penangkap ikan, namun karena kesombongannya, salah seorang warga memantrai lukahnya agar ikan tangkapannya tumpah, melihat lukah yang dimantrai tersebut dapat bergerak sendiri tanpa digerakkan, lalu munculah ide untuk membuat kesenian dengan menggunakan lukah (Wawancara dengan Buya Herdian Fauzi 26 April 2018).

Tari Lukah Gilo sering ditampilkan bukan hanya untuk melestarikan kebudayaan itu sendiri, akan tetapi juga untuk menguji ketangkasan dari anak-anak muda. Pertunjukan biasanya dilaksanakan pada malam hari. Menurut kulipah, waktu malam hari dianggap tepat untuk memanggil jin yang akan dimasukkan ke dalam lukah, sehingga menyebabkan pertunjukan lukah gilo ini terasa semakin magis. Penyajian tari Lukah Gilo melalui proses yang unik dan dilakukan melalui tiga tahap, yaitu (1) proses persiapan yang meliputi mempersiapkan lukah, lukah direndam, lukah dipakaikan baju dan dihias, (2) pelaksanaan atau pementasan dipimpin oleh kulipah dengan menghadirkan jin untuk meng-gilo-kan lukah, (3) penutup untuk mengembalikan para jin ke tempat semula.

Konsep pelaksanaan tari Lukah Gilo terkait dengan fatwa yang berbunyi adaik manurun, syarak mandaki (adat turun, agama naik) atau dengan arti bebas: adat turun dari pedalaman (yang juga disebut darek) ke pesisir atau dari luhak ke rantau, sedangkan agama naik dari pesisir ke pedalaman (Desfiarni, 2004: 111). Tari Lukah Gilo erat kaitannya dengan kepercayaan animisme dan dinamisme, seperti tampak dari penggunaan mantera-mantera serta kepercayaan terhadap arwah nenek moyang (Hamka, 1984: 7-16).

Sebelum mengalami perkembangan, pertunjukan tari Lukah Gilo dipentaskan apa adanya, tanpa ada penambahan unsur pendukung seperti iringan musik dan busana. Konsep garapan iringan dipilahkan menjadi dua, yaitu bentuk yang eksternal ataupun internal. Bentuk eksternal iringan hadir dari luar diri penari, sedangkan internal iringan datang dari tubuh penari misalnya dengan tepukan, vokal, dan sebagainya (Sal Murgiyanto, 1977: 132). Iringan tari Lukah Gilo terdiri dari beberapa alat musik yaitu, enam pencu talempong, dan satu buah kendang.

Pada awalnya lukah tidak diberi busana. Namun saat ini busana yang dikenakan ke lukah yaitu kebaya, sisampiang (sarung sebatas lutut), kain panjang sebagai jilbab, dan kain panjang yang diikatkan di pinggang lukah. Pada bagian kepala menggunakan labu air yang dihias dengan membuat simbol mata, hidung dan mulut dengan menggunakan sadah (kapur sirih). Busana penari terdiri dari: bagian kepala penari menggunakan deta batik berbentuk tanduk, mengenakan baju taluak belanga (kemeja longgar berwarna hitam) dengan aksen motif berwarna emas, serawa panjang (celana), dan sisampiang (sarung sebatas lutut), dan mengenakan salempang atau selendang. Perbedaan busana yang dipakai oleh kulipah dengan pendukung lainnya adalah pakaian kulipah yang serba hitam, melambangkan kekuatan gaib.

Pelaku pertunjukan Lukah Gilo dibagi menjadi dua bagian, yaitu penari dan kulipah. Semua pendukung tari Lukah Gilo berjenis kelamin laki-laki, karena kaum lelaki dianggap memiliki tenaga yang kuat untuk mengendalikan gerakan lukah gilo. Bentuk penyajian bisa diartikan sebagai wujud atau gambaran tentang sesuatu yang dipertunjukkan kepada umum. Dalam tari Lukah Gilo tahapan-tahapan proses yang terbagi menjadi tiga macam tahapan menjadi elemen-elemen 
penting pada tiap bagiannya, sehingga nantinya elemen tersebut akan membentuk satu kesatuan yang tidak lepas dari bagianbagian terbesar sehingga didapatkan suatu rangkaian yang teratur dalam sebuah penyajian (Jacqueline Smith, 1985: 21), sehingga orang lain akan mudah memahami bagaimana bentuk penyajian dari sebuah komposisi tari yang diwujudkan untuk menghasilkan bentuk keseluruhan. Alasan dipilihnya tarian tersebut karena keberadaan tari Lukah Gilo yang masih sangat dijaga kelestariannya sekaligus sebagai identitas budaya masyarakat Minangkabau khususnya pada masyarakat Sijunjung.

Menurut teori budaya, ada dua macam budaya yang sulit diubah, yaitu budaya yang berkaitan dengan kepercayaan atau adat lokal, dan budaya yang sudah sejak lama dibiasakan (David Kaplan, 1999: 181-193). Adapun yang membuat tarian ini tetap dijaga kelestariannya adalah karena keunikan yang sekaligus menjadi identitas budaya masyarakat Minangkabau. Tari Lukah Gilo merupakan warisan nenek moyang yang tidak dapat musnah sekalipun terjadi pemurnian agama Islam, ibarat pepatah mengatakan: indak lapuak dek hujan, indak lakang dek paneh (tidak lapuk karena hujan, tidak lekang karena panas).

Berdasarkan pada latar belakang masalah yang telah dikemukakan, maka permasalahan yang akan diteliti adalah bagaimana bentuk penyajian tari Lukah Gilo di masyarakat Sijunjung, Sumatera Barat? Adapun tujuan penelitian yaitu ingin mengetahui, menganalisis dan mendeskripsikan bentuk penyajian tari Lukah Gilo di Masyarakat Sijunjung, Sumatera Barat.

\section{Bentuk Penyajian Tari Lukah Gilo}

Bentuk penyajian adalah sesuatu yang disajikan dalam bentuk tari yang telah ditata mencakup dengan beberapa komponen bentuk penyajian yang saling berkaitan, yang meliputi dasar penyajian, tata gerak, tata iringan, tata pentas, dan tata rias busana. Pengertian bentuk penyajian tidak pernah lepas dari pengertian kata "bentuk" dan "penyajian". Dalam Kamus Umum Bahasa Indonesia kata bentuk mempunyai pengertian sebagai "wujud yang ditampilkan" (WJS Poerwadaminta, 1976: 122).

Jaqueline Smith dalam bukunya Dance Composition: A Practical Guide For Teachers terjemahan Ben Soeharto Komposisi Tari: Sebuah Petunjuk Praktis Bagi Guru, menjelaskan tentang kata bentuk adalah sesuatu yang dapat dibedakan dari materi yang telah ditata (Jacqueline Smith, 1985: 6), di mana suatu komposisi diatur atau diwujudkan untuk menghasilkan bentuk keseluruhan. Bentuk keseluruhan tersebut meliputi elemenelemen yang nantinya akan membentuk satu kesatuan yang tidak lepas dari bagian-bagian suatu komposisi tari sehingga didapatkan suatu rangkaian yang teratur dalam sebuah penyajian.

\section{A. Tema}

Tema merupakan ide pokok dari sebuah penciptaan karya, dalam hal ini tema merupakan makna yang terkait dalam sebuah tari. Seorang penata tari mendapatkan sebuah rangsang gerak melalui tema atau ide-ide yang hadir.

Tema dalam tari Lukah Gilo diangkat dari kehidupan sehari-hari, kehidupan yang dialami oleh masyarakat Sijunjung yang bernama Duhak. Duhak yang mata pencahariannya berladang sering pergi ke 
sungai untuk menangkap ikan dengan menggunakan lukah. Setiap pulang dari sungai ia selalu membawa hasil tangkapan yang melimpah, namun setiap menuju rumahnya dan melewati rumah warga, Duhak tidak pernah menegur warga setempat atau sekedar untuk berbagi hasil tangkapannya. Hal tersebut membuat salah seorang warga yang mempunyai ilmu untuk memanggil jin, berniat untuk memberikan pelajaran kepada Duhak. Orang tersebut diam-diam mengambil lukah yang sering digunakan oleh Duhak untuk menangkap ikan sehari-hari, lukah tersebut kemudian diberi mantra atau di-gilokan agar tangkapan ikannya tumpah, dan ternyata mantra untuk meng-gilo-kan lukah tersebut berhasil dan setiap Duhak mendapatkan tangkapan ikan yang melimpah, lukah-nya selalu bergerak-gerak sendiri sehingga ikan hasil tangkapannya tumpah. Menyadari kejadian tersebut, lalu Duhak meminta maaf kepada warga yang tidak pernah ia sapa setiap ia lewat di depan rumah mereka (Wawancara dengan Buya Herdian Fauzi 26 April 2018). Lukah yang bergerak dengan sendirinya setelah diberikan mantera membuat warga terinspirasi untuk menciptakan kesenian yang bersumber dari lukah. Penggunaan properti lukah tersebut melambangkan tentang kekuatan supranatural. Meskipun di dalamnya mengandung asal usul yang berkaitan dengan kekuatan supranatural, namun dalam tari Lukah Gilo tidak memiliki cerita khusus pada proses penyajiannya.

\section{B. Urutan Penyajian}

Tari Lukah Gilo merupakan kesenian warisan nenek moyang yang masih tetap hidup dan berkembang di masyarakat Minangkabau, khususnya masyarakat Sijunjung. Pada permainannya, tari Lukah
Gilo lebih menonjolkan sisi permainan lukah (bubu) yang telah dibacakan mantra dan pertunjukannya dipimpin oleh kulipah (pawang).

Pada saat penelitian tari Lukah Gilo dipentaskan di halaman sanggar Sarunai Sangkokalo di Palangki, Sijunjung sebagai latihan rutin yang diadakan oleh sanggar untuk mengasah keterampilan anggota sanggar. Seperti yang sudah dijelaskan sebelumnya, selain dipentaskan di acara-acara tertentu, seperti acara 17 Agustus, pesta adat, pengangkatan penghulu, penyambutan tamu, dan lain sebagainya, tari Lukah Gilo sering dipentaskan di halaman rumah warga atau sanggar sebagai pertunjukan hiburan semata bagi warga sekitar atau pendukung sanggar tersebut. Hal ini dilakukan tak lain sebagai upaya untuk melatih kemampuan masyarakat, anak-anak muda, atau anggota sanggar dalam berkesenian khususnya dalam mengontrol lukah pada tari Lukah Gilo dan seni bela diri.

Pada bentuk keseluruhan tari Lukah Gilo di Sijunjung memiliki pembagian dalam penyajiannya. Pembagian tersebut terdiri atas 3 (tiga) tahapan yaitu:

\section{Tahap Persiapan}

Pada tahap ini yang harus dilakukan adalah mempersiapkan kebutuhan untuk menghias lukah yang akan digunakan sekaligus sebagai media utama dalam pertunjukan tari Lukah Gilo. Bahan yang harus dipersiapkan terdiri dari lukah sebagai badan, labu air sebagai kepala, satu buah pelepah pisang sebagai tangan, sadah (kapur sirih) sebagai media untuk membuat mata, hidung, dan mulut lukah, serta mempersiapkan kostum lukah yaitu kebaya, sisampiang, kain panjang yang akan digunakan sebagai jilbab, dan kain panjang yang akan digunakan sebagai ikat pinggang. 


\section{JOGED}

ISSN: $1858-3989$
Lukah dibeli, lalu direndam di dalam air selama \pm 30 menit sebagai simbol dari fungsi lukah tersebut yaitu sebagai alat penangkap ikan (Wawancara dengan Buya Herdian Fauzi 30 April 2018).

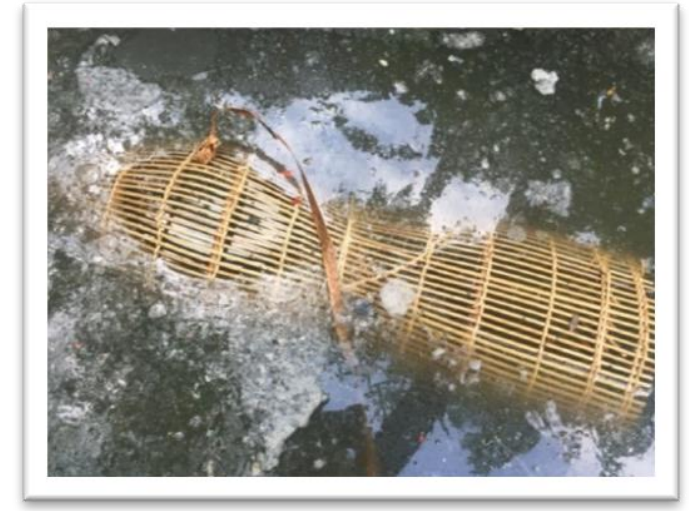

Gambar 1. Lukah (bubu) direndam di dalam air (Foto: Devi Kurnia Santi, 30 April 2018)

Pertunjukan tari Lukah Gilo di masyarakat Sijunjung tidak menggunakan sesaji. Hal ini dikarenakan pertunjukan tari Lukah Gilo hanya sebagai sarana hiburan semata walau tanpa meninggalkan unsur magis di dalam tarian tersebut. Menurut Buya Herdian Fauzi bahwa tidak adanya sesaji dikarenakan beliau tidak ingin menuhankan jin yang dimasukkan di dalam lukah selama pertunjukan berlangsung, jin yang akan dimasukkan ke dalam lukah justru diberi ancaman atau ditakut-takuti dengan membisikkan mantera dari kulipah. Hal tersebut yang lantas membuat lukah menjadi marah dan bergerak tak terkendali.

Hal selanjutnya yang disiapkan yaitu labu air. Labu air yang digunakan merupakan labu yang telah dikeringkan dan kosong sebagai simbol kepala lukah. Gerakan Lukah Gilo yang sangat atraktif terkadang membuat labu tersebut pecah ketika lukah jatuh ke tanah, sehingga labu tersebut tidak dapat digunakan lagi untuk pertunjukan selanjutnya. Biasanya pertunjukan terpaksa dihentikan. Apabila pertunjukan akan tetap diteruskan, maka orang akan mencari labu pengganti. Sayangnya, keberadaan labu ini sudah sangat sulit didapatkan, hanya orangorang tertentu yang memiliki dan biasanya hanya sebagai koleksi semata.

Proses menghias lukah dilakukan dengan sangat teliti dan hati-hati. Proses ini dilakukan oleh kulipah, proses pertama yaitu memasang labu air yang diikat di bagian ujung lukah yang berbentuk kerucut, labu tersebut sebagai simbol kepala lukah, kemudian memasangkan pelepah pisang sebagai simbol tangan, setelah itu memakaikan kebaya dan sisampiang (sarung yang dipakai sebatas lutut), lalu pada bagian kepala dipakaikan jilbab, dan diikatkan kain pada bagian pinggang, untuk membuat simbol mata, hidung dan mulut kulipah menggunakan sadah (kapur sirih).
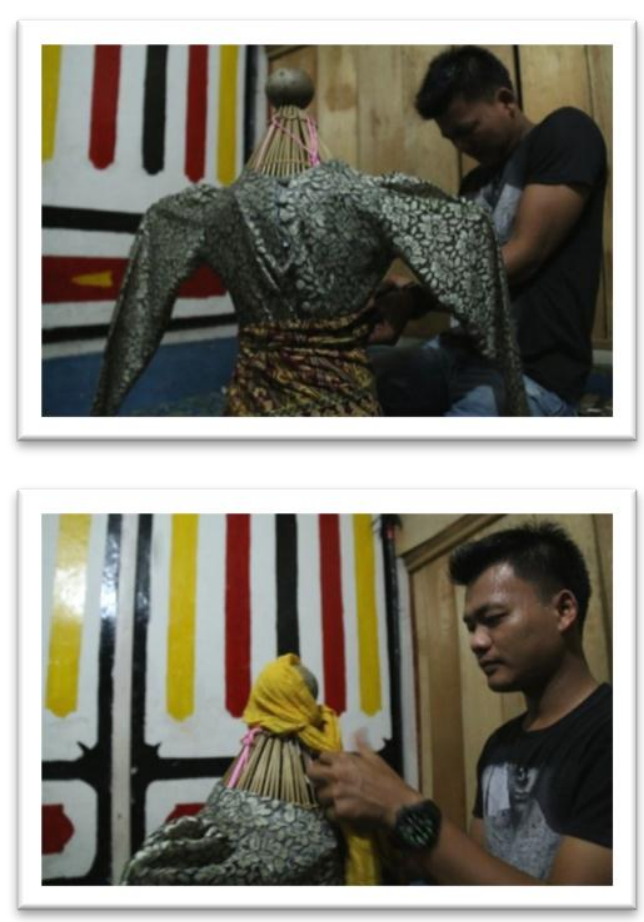
Gambar 2. Pemakaian sisampiang (sarung setengah lutut) (kiri), pemakaian kain panjang sebagai jilbab (kanan) (Foto: Tommi, 30 April

\section{8)}
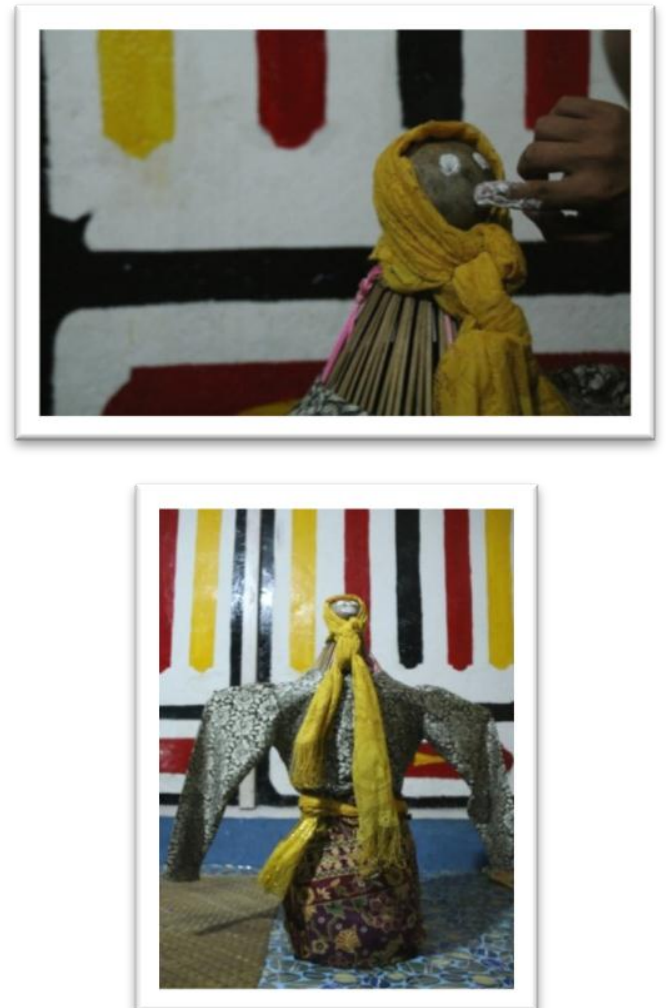

Gambar 3. Pembuatan simbol mata, hidung, dan mulut lukah menggunakan sadah (kiri),

Lukah yang telah selesai dirias (kanan). (Foto: Tommi, 30 April 2018).

\section{Tahap Pelaksanaan}

Pertunjukan tari Lukah Gilo di masyarakat Sijunjung diawali dengan menampilkan tari silat khas daerah Sijunjung, yaitu Silat Langkah Ampek, Silat Parang Ladiang, dan Silat Pedang. Pertunjukan silat dipentaskan untuk menghangatkan suasana sebelum pertunjukan tari Lukah Gilo ditampilkan. Silat dimasukkan ke dalam bagian pertunjukan tari Lukah Gilo dikarenakan gerakan silat memiliki pengaruh pada saat mengendalikan lukah gilo, dan sebagaimana pertunjukan lukah gilo yang ditampilkan bukan hanya sebagai sarana hiburan, akan tetapi juga untuk menguji ketangkasan dari anak-anak muda dan masyarakat Minang dalam mengontrol lukah yang telah diberi mantera. Durasi waktu pertunjukan silat lebih kurang tujuh menit yang ditarikan oleh dua orang penari laki-laki. Setelah pertunjukan silat selesai akan diberi jeda sebentar sebelum pertunjukan tari Lukah Gilo dipentaskan.
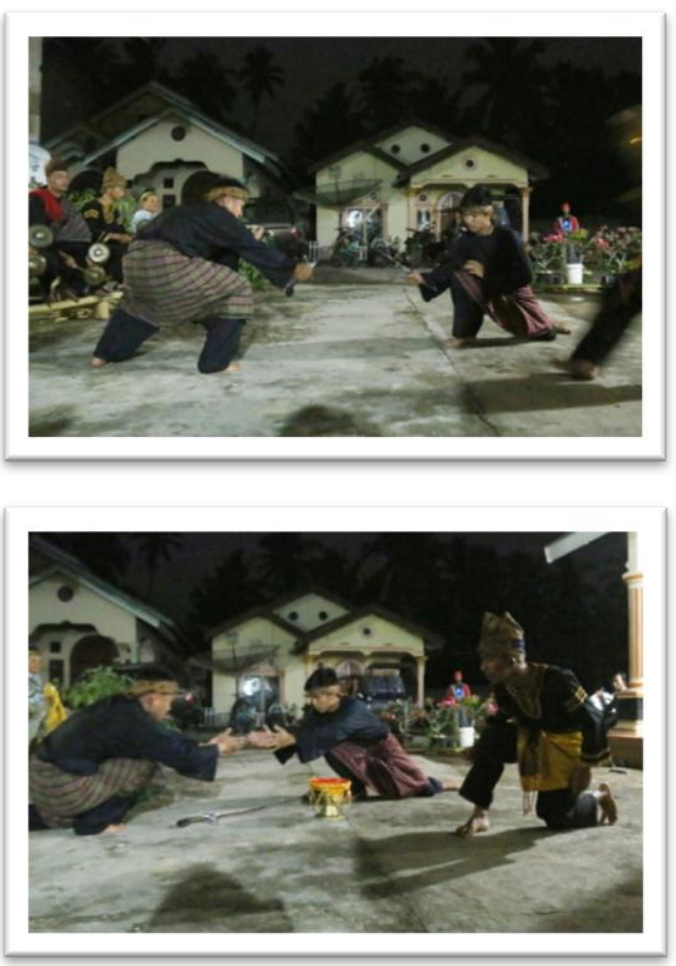

Gambar 4. Kedua penari menarikan silat pedang (kiri), penyerahan cerano oleh salah satu penari yang menyimbolkan perdamaian (kanan). (Foto: Tommi, 30 April 2018)

Tanda pertunjukan tari Lukah Gilo dimulai yaitu ketika kulipah mulai memasuki tempat pertunjukan dengan membawa lukah yang telah dihias yang kemudian diletakkan di tengah tempat pertunjukan, dan diiringi dengan iringan musik yang tidak akan berhenti sepanjang 
pertunjukan berlangsung. Mantra yang dibisikkan di sini merupakan mantra yang dirahasiakan oleh kulipah. Pada saat memberikan mantera dengan cara dibisikkan, lukah tidak akan langsung bergerak sehingga kedua penari atau pemegang lukah tersebut akan menggoyang-goyangkan lukah untuk memancing jin yang akan masuk ke dalam lukah, setelah merasakan ada kekuatan lain yang menggerakkan lukah maka kedua penari tersebut akan segera berdiri untuk mengikuti pergerakan lukah, dan apabila lukah tidak dapat dikendalikan maka penari lainnya akan segera merespons dengan ikut memegang untuk mengendalikan Lukah Gilo.
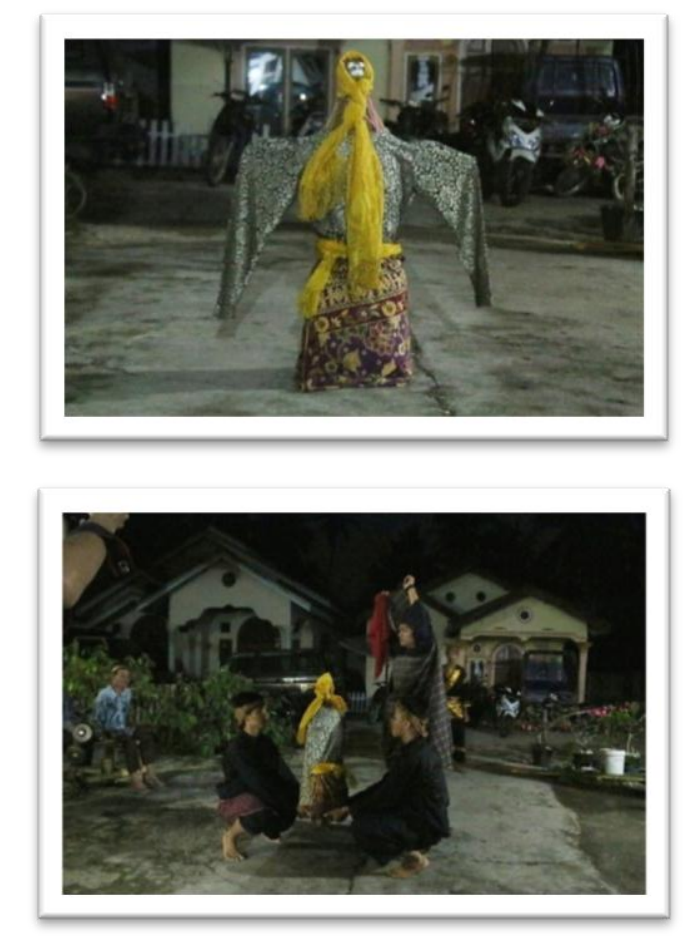

Gambar 5.. Lukah yang telah dihias dibawa ke tengah tempat pertunjukan (kiri), kedua penari dengan posisi jongkok memegang lukah (kanan).

(Foto: Tommi, 30 April 2018)

Peran kulipah sangat berpengaruh pada jalannya pertunjukan. Ketika jin telah masuk ke dalam lukah, pada saat itu juga untuk membuat lukah bergerak atraktif kulipah akan mendendangkan mantra yang didendangkan secara terbuka dan mengarahkan gerakan lukah melalui kain merah yang dibawa oleh kulipah. Adapun mantra yang didendangkan secara terbuka oleh kulipah sebagai berikut:

\section{Silewasi anak Simalin Sialuka} Nandiam di ulu lembang bangko Apo karajo sari sahari Intang marawik-rawik rotan

\section{Rotan ka panjolai luka} Nan Siluka banyak ulahnyo Galianggang tumbuo di bukik Anak capo tumbuo di lombak Malenggang luka sadikik Maliek parangai Allah

Anak kumbang si donguong-donguong Basarang di buluo minyak Jan luka duduok ta monouong Jan ragu dek urang banyak

Nak kambieng sitiku titi Daun katari gumpo jangan Pikiri di dalam ati Bisiek nan tadi lupo jangan

Den titi tatian tolang

Den titi duo baduo

Rancak kain dek basolang

Licin obouok den minyak baminto

Gilo sipasin gilo

Gilo dek si tawang-tawang

Gilo si luka gilo

Gilo di aga bayang-bayang

Gilo si kanduang dek ei

Gilo si luka gilo

Caoek sabua dek rang katokan

Tiduo pakalang cirik ayam 
Bapakasi tanah banda aie

Gilo si luka gilo

Ontak kan pagara ruyuang

Gilo si luka gilo

Campakkan labu di jujuang

Di mano rotan nan panjang

Dalam lurah kalo bakalo

Di mano setan nan godang

Dalam luka sadang manggilo

Mantra tersebut akan terus didendangkan oleh kulipah selama Lukah Gilo masih bergerak, namun jika lukah sudah terjatuh maka seketika kulipah juga akan berhenti mendendangkan mantra tersebut.
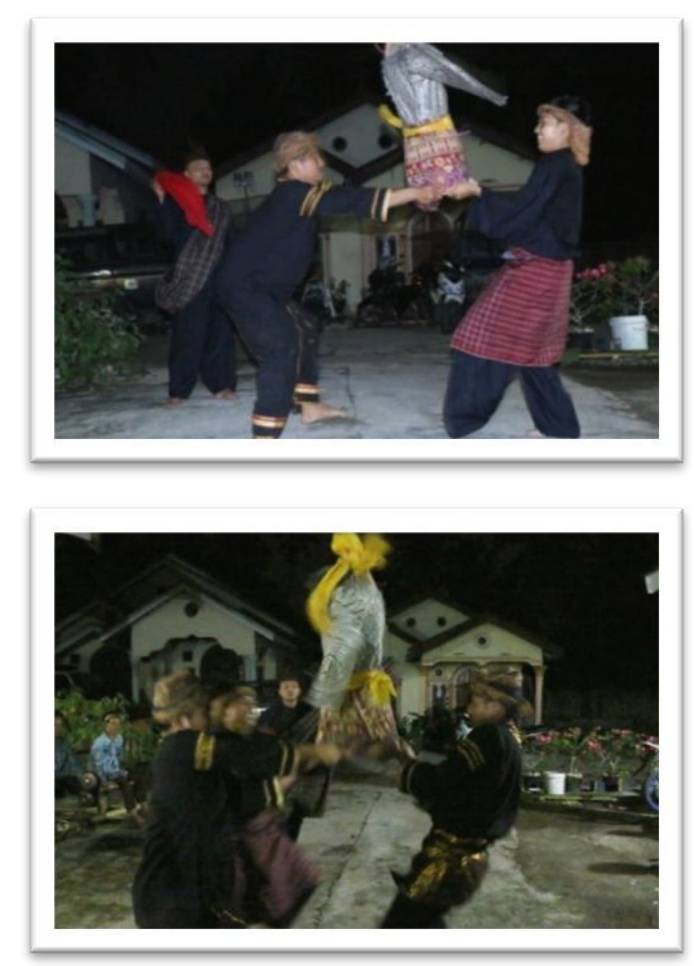

Gambar 6. Kulipah memandu gerakan Lukah Gilo dengan menggerakkan kain merah (kiri), penari bersama-sama mengendalikan Lukah Gilo (kanan) (Foto: Tommi, 30 April).

\section{Tahap Penutup}

Penutup adalah cara untuk memulangkan jin ke tempat semula, namun tidak setiap pertunjukan tari Lukah Gilo jin harus dipulangkan oleh kulipah, terkadang jin akan pergi dengan sendirinya ketika lukah jatuh atau penari sudah merasa lelah, sehingga melepaskan lukah tersebut. Pertunjukan Lukah Gilo tidak hanya dilakukan satu kali, tetapi berkali-kali, setiap pertunjukannya tidak memiliki batasan waktu, gerakan Lukah Gilo tidak dapat diprediksi, dan kekuatan penari atau pemegang lukah tergantung pada setiap individu. Pertunjukan Lukah Gilo akan terus berlangsung selama penari atau pemegang lukah masih mampu mengendalikan lukah, namun jika sudah tidak mampu, kulipah akan menghentikan pertunjukan dengan membacakan mantra agar lukah tersebut berhenti bergerak, atau penari akan melepaskan lukah dengan sendirinya, dengan demikian pertunjukan pun berakhir yang ditandai alunan musik yang berhenti.

\section{Tata Gerak}

Pada tahap pelaksanaan sebelum tari Lukah Gilo dilaksanakan terlebih dahulu akan ke luar beberapa penari untuk mengawali pertunjukan tari Lukah Gilo dengan mempertunjukkan gerak Silat Minang. Silat merupakan seni beladiri yang dimiliki oleh masyarakat Minangkabau, yang diturunkan secara turun temurun dari generasi ke generasi. Gerak silat yang dilakukan yaitu Silat Langkah Ampek, Silat Parang Ladiang, dan Silat Pedang. Adapun nama-nama motif gerakannya yaitu:

\section{Silat Langkah Ampek}

Sebelum melakukan gerakan pada silat langkah ampek, terlebih dahulu kedua penari akan bersalaman dan masing-masing 
penari akan membaca surah Al- Fatihah, kemudian melakukan gerakan dengan motif penyembahan. Penyembahan memiliki arti sebagai simbol untuk saling meminta maaf, dan mohon izin.
a. Panjek Sigei
b. Patah Tebu
c. Kungkung Batak

\section{Silat Parang Ladiang}

Silat ini menggambarkan orang gila yang sedang mengamuk dan membawa parang (golok) dan ladiang (pisau), sehingga gerakannya pun tidak beraturan. Gerak dalam silat ini merupakan gerak yang memiliki maksud untuk menenangkan orang gila yang sedang mengamuk tersebut. Silat ini tercipta agar suatu saat nanti jika bertemu dengan orang gila yang dapat membahayakan orang lain atau diri sendiri dapat digunakan untuk menangkap orang gila tersebut tanpa ada unsur kekerasan.

\section{Silat Pedang}

a. Motif Bersikudidi

b. Penyembahan

Penari melakukan gerakan dari ketiga jenis silat di atas, penari silat akan terus menarikan gerak-gerak silat sampai seseorang datang membawa cerano. Cerano memiliki arti sebagai simbol perdamaian antar dua penari yang telah bertarung. Pemberian cerano dimaksudkan agar setelah kedua penari silat selesai bertarung mereka akan berdamai dan tidak memiliki dendam satu sama lain.

Gerak pada tari Lukah Gilo merupakan gerak murni dan gerak responsif atau gerak spontan dari rangsang pengendalian properti lukah (bubu) yang telah diberi mantera. Gerak murni yaitu gerakan yang tidak mengandung maksud atau artian tertentu, sedangkan gerak responsif adalah gerak merespons properti yang dipegang oleh penari.
Penari akan ikut bergerak mengikuti pergerakan dari lukah tersebut. Gerak pada penari sekaligus bentuk spontan dari pengendalian lukah yang dipegang oleh penari secara bersama-sama. Gerak tari Lukah Gilo banyak ditekankan pada kekuatan gerak kaki dan tangan pada saat mengendalikan lukah yang telah diberi mantra oleh kulipah. Gerak tersebut seperti bergeser, berputar, maju ke depan, mundur ke belakang, atau ke samping kanan dan kiri. Selanjutnya, pertunjukan dalam tarian ini akan tetap mengelompok mengelilingi lukah yang dipegang bersamasama. Gerak tari Lukah Gilo pada dasarnya mengikuti arahan dari kulipah yang membawa kain merah, dan irama dari iringan musik pengiring sebagai motivasi semangat pada gerak Lukah Gilo. Segala gerak yang tercipta merupakan gerak spontan dalam mengendalikan lukah yang telah diberi mantra.

\section{Tata Rias dan Busana}

Pada tari Lukah Gilo ada tiga jenis rias dan busana dalam pertunjukannya, yaitu rias dan busana lukah, rias dan busana kulipah, serta rias dan busana penari atau pendukung. Tari Lukah Gilo riasan hanya dipakaikan pada lukah, yaitu dengan memberi simbol gambar mata, hidung, dan mulut menggunakan sadah (kapur sirih) pada kepala lukah yang terbuat dari labu. Busana yang dipakai oleh lukah adalah kebaya, sisampiang (sarung yang dipakai setengah lutut), jilbab, pelepah pisang (sebagai tangan), dan kain yang diikat di bagian pinggang lukah.

Busana yang dipakai oleh kulipah dengan pendukung lainnya adalah pakaian yang serba hitam, melambangkan kekuatan ghaib. Busana yang dikenakan kulipah yaitu baju taluak balango (kemeja longgar berwarna hitam), serawa (celana) hitam panjang. Pada bagian kepala kulipah memakai peci berbulu 
berbentuk bulat dan runcing di bagian atas. Selama pertunjukan kulipah akan membawa kain berwarna merah dan sarung, kain merah ini difungsikan sebagai media untuk mengarahkan pergerakan Lukah Gilo, jika kulipah menggerakkan kain merah tersebut ke atas maka gerakan Lukah Gilo akan semakin tinggi, namun jika kulipah menggerakkan kain merah tersebut dengan memutar maka pergerakan Lukah Gilo akan bergerak ke mana-mana (Wawancara dengan Buya Herdian Fauzi 01 Mei 2018). Sarung digunakan oleh kulipah sebagai media penutup saat kulipah sedang membisikkan mantra kepada lukah.

Busana yang dikenakan oleh penari dibagi menjadi 2 (dua) kelompok, yaitu busana untuk penari silat dan busana untuk penari pengendali Lukah Gilo. Busana yang dikenakan oleh penari silat yaitu mengenakan baju taluak balango (kemeja longgar berwarna hitam), serawa (celana) hitam panjang, sisampiang (sarung setengah lutut), dan pada bagian kepala mengenakan deta batik. Busana yang dikenakan oleh penari pengendali Lukah Gilo yaitu baju taluak balango (kemeja longgar berwarna hitam) dengan aksen motif berwarna emas, mengenakan celana galembong, salempang atau selendang, sisampiang, dan pada bagian kepala mengenakan deta batik yang dibentuk seperti tanduk. Secara keseluruhan tidak ada hiasan wajah baik untuk kulipah, penari silat, dan penari Lukah Gilo.
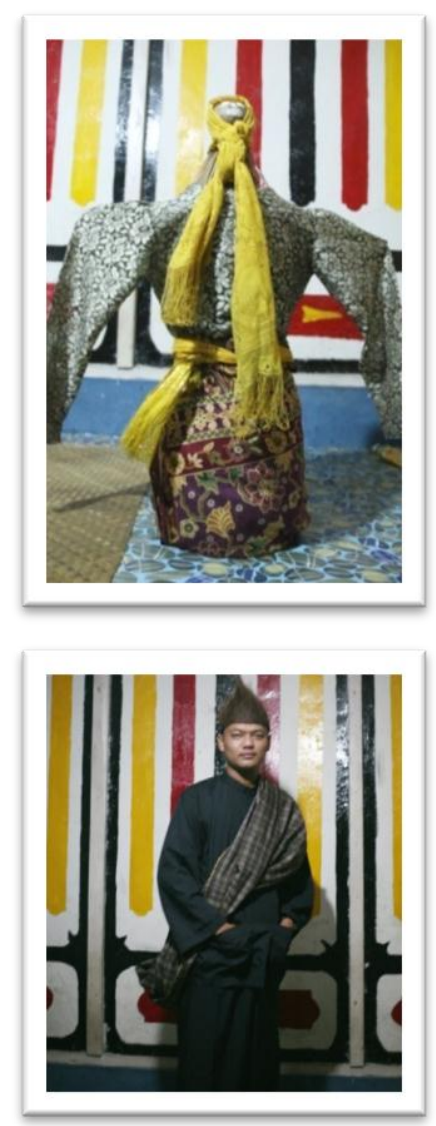

Gambar 11. Foto rias dan busana lukah (kiri), foto busana kulipah (kanan). 


\section{JOGED}

ISSN: $1858-3989$
(Foto: Tommi, 30 April 2018)
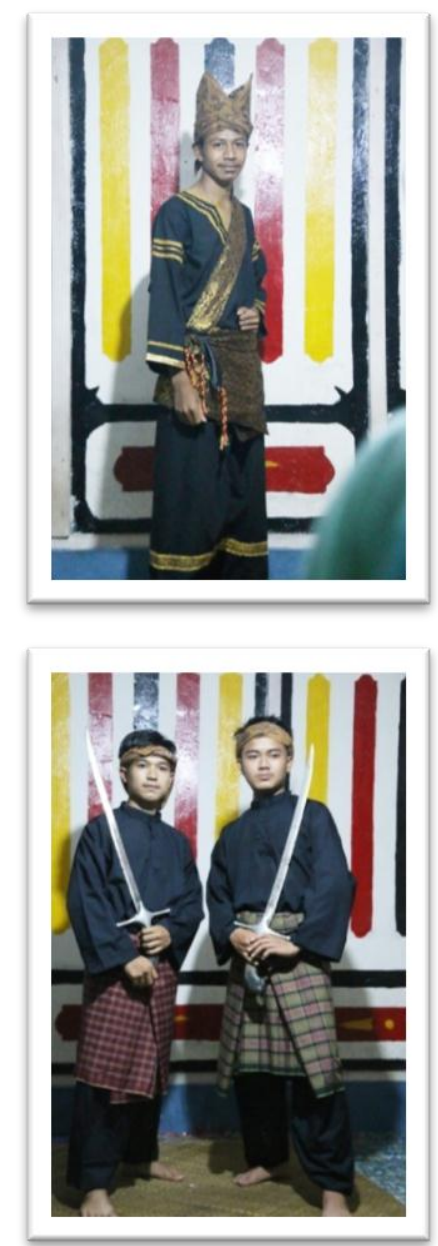

Gambar 12. Foto busana penari pengendali Lukah Gilo (kiri), Foto busana penari Silat (kanan).

(Foto: Tommi, 30 April 2018).

\section{E. Tata Iringan}

Tari Lukah Gilo mengalami perkembangan yang signifikan pada unsur pendukungnya, termasuk pada iringannya, jika dahulu pertunjukan tari Lukah Gilo tidak diiringi dengan alat musik, kini unsur-unsur pendukung seperti alat musik dimasukkan dengan tujuan agar pertunjukan tari Lukah Gilo menjadi lebih menarik perhatian penonton. Selain itu juga, pada tari Lukah Gilo iringan sekaligus menjadi pemacu semangat pada gerakan lukahnya. Iringan pertunjukan tari Lukah Gilo terbilang sederhana, instrumen yang dipergunakan untuk mengiringi pertunjukan tari Lukah Gilo terdiri dari enam pencu talempong dan kendang. Enam pencu talempong dimainkan oleh tiga orang pemusik yang masing-masing pemusik akan memainkan sepasang talempong. Talempong dimainkan dengan cara dipukul, bunyi yang dihasilkan sebagai ritme pengiring tari Lukah Gilo yang memberikan kesan spirit dan untuk menghidupkan suasana khas Minangkabau. Kendang dimainkan oleh satu orang. Bunyi yang dihasilkan dari kendang sebagai penekanan untuk setiap pergerakan lukah yang bergerak bebas setelah dibacakan mantra oleh kulipah.

\section{F. Tata Pentas}

Tempat pementasan atau pertunjukan selalu disesuaikan dengan keadaan dari bentuk pertunjukan yang hendak disajikan. Seperti halnya pada tari Lukah Gilo yang dipentaskan di lapangan atau halaman terbuka (rumah warga yang memiliki hajat). Tempat pementasan atau pertunjukan tari Lukah Gilo tidak hanya dapat dipentaskan di dua tempat tersebut, melainkan dapat dipentaskan di mana saja sesuai dengan situasi dan kondisi, serta permintaan yang punya hajat. Konsep pementasan dengan arena terbuka dimaksudkan agar kesenian rakyat ini dapat dinikmati dan disaksikan oleh banyak warga yang terlibat sebagai penonton, selain itu sebuah arena pertunjukan memang digelarkan untuk pentas seluruh penyajiannya, baik dari awal pertunjukan maupun akhir dari pertunjukan tersebut. Tempat pementasan tari Lukah Gilo ini dipertunjukkan di halaman sanggar Sarunai Sangkokalo di Palangki, Sijunjung, Sumatera Barat. Luas area pertunjukannya berukuran \pm 5 x 7 meter $^{2}$ yang di setiap sisi halamannya dimanfaatkan untuk menonton pertunjukan ini. 


\section{G. Pola Lantai}

Pertunjukan tari Lukah Gilo merupakan pertunjukan yang melibatkan banyak pemain. Pertunjukan tari Lukah Gilo di Sijunjung akan diawali dengan pertunjukan Silat. Tiga jenis silat yang dilakukan yaitu Silat Langkah Ampek yang terdiri dari motif gerak Penyembahan, Panjek Sigei, Patah Tebu, Kungkung Batak, Silat Parang Ladiang, dan Silat Pedang yang terdiri dari motif gerak Penyembahan, dan Bersikudi.

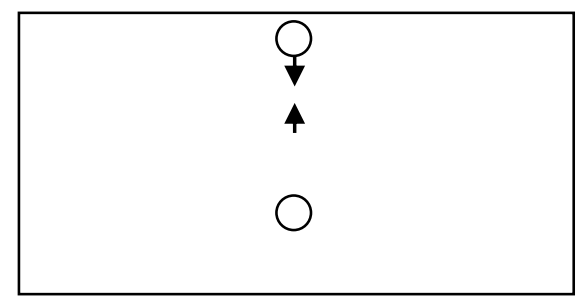

Gambar 20. Pola lantai Silat Langkah Ampek

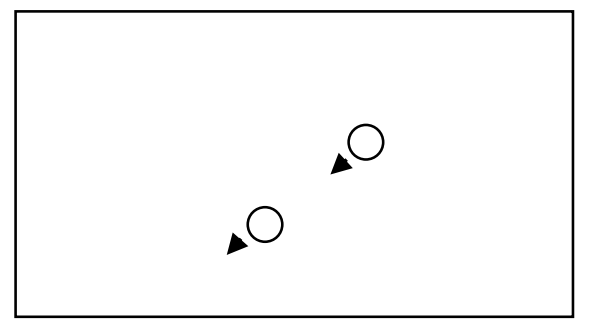

Gambar 21. Pola lantai Silat Langkah Ampek motif gerak Penyembahan

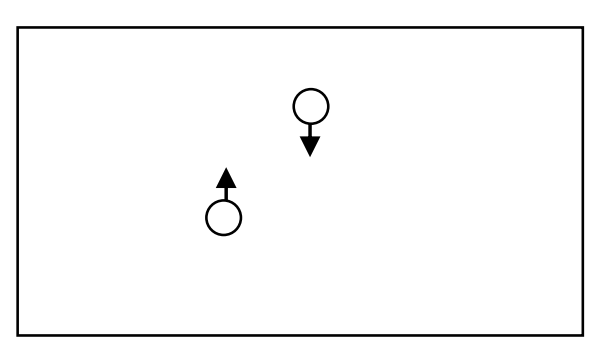

Gambar 22. Pola lantai Silat Langkah Ampek motif gerak Panjek Sigei

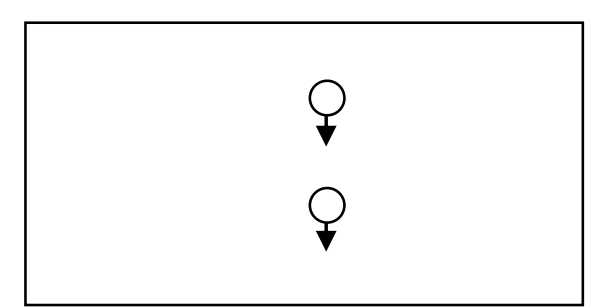

Gambar 23. Pola lantai Silat Langkah Ampek motif gerak Patah Tebu

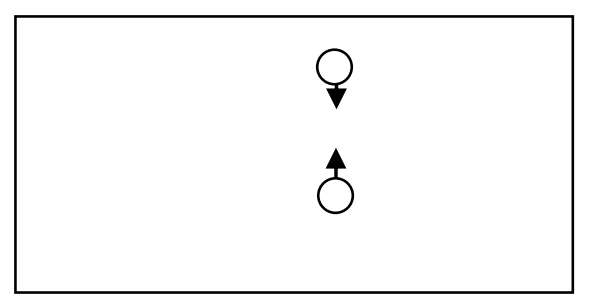

Gambar 24. Pola lantai Silat Langkah Ampek motif gerak Kungkung Batak

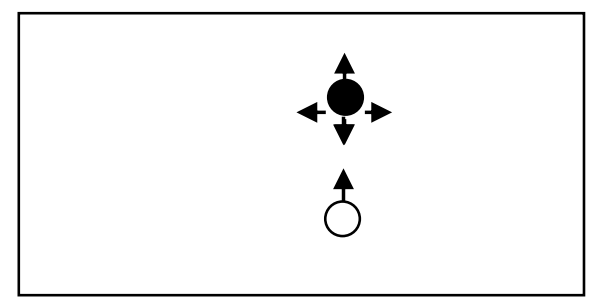

Gambar 25. Pola lantai Silat Parang Ladiang (salah satu penari berbaring memutar badannya, salah satu penari membawa golok untuk membacok penari yang sedang berbaring)

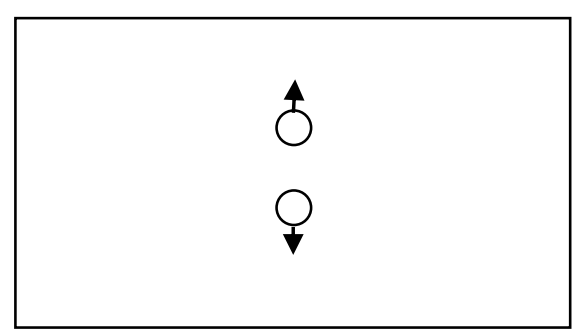

Gambar 26. Pola lantai Silat Parang Ladiang (kedua penari dalam posisi berlawanan)

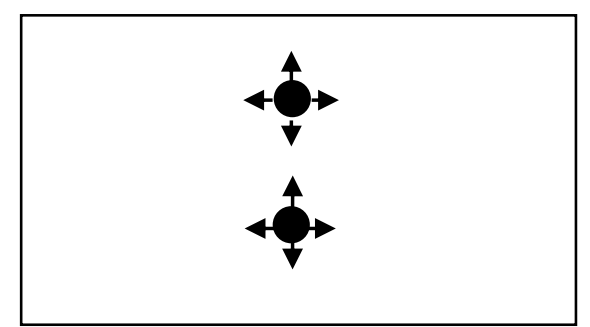

Gambar 27. Pola lantai Silat Parang ladiang (Penari saling berlarian)

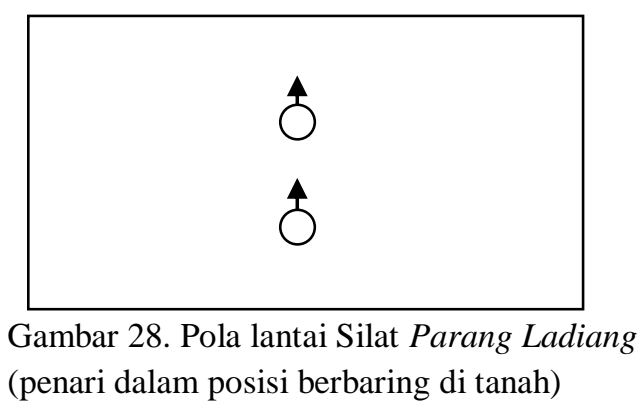




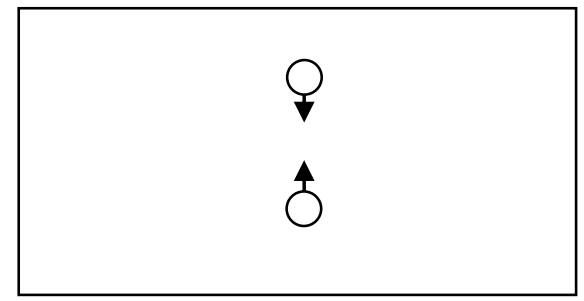

Gambar 29. Pola lantai Silat Pedang motif gerak Penyembahan

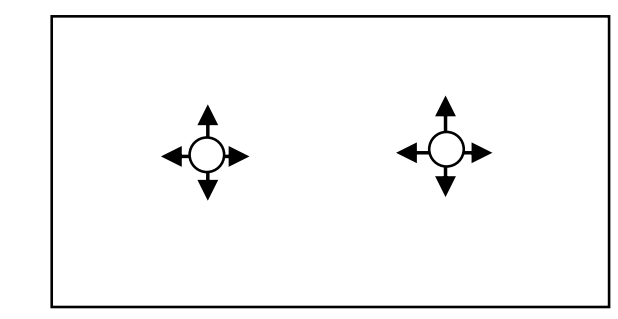

Gambar 30. Pola lantai Silat Pedang motif gerak Bersikudidi

Pola lantai awal pada tari Lukah Gilo dimulai dengan kedua penari dengan posisi jongkok saling berhadapan memegang lukah. Pola lantai selanjutnya mengikuti gerak Lukah Gilo yang telah diberi mantra yaitu menggunakan pola melingkar. Pola melingkar ini akan terus berlangsung selama pertunjukan tari Lukah Gilo belum selesai atau berhenti. Pertunjukan tari Lukah Gilo yang mengandung kekuatan magis memiliki hubungan dengan pola berbentuk lingkaran yang sekaligus sebagai simbol kekuatan dan pertahanan saat mengendalikan Lukah Gilo secara bersamasama. Hal tersebut sama seperti pendapat Soedarsono, bahwa tari tradisi baik tari ritual atau tari hiburan, dan ditarikan secara kelompok dapat dikatakan masih memperlihatkan ciri-ciri primitifnya. Hal tersebut ditandai dengan pola lantai mengelompok melingkar yang dipercaya oleh sebagian pemilik tari tersebut memiliki daya magis yang mempengaruhi berlangsungnya pertunjukan tarian tersebut (R.M Soedarsono, 1974: 82).

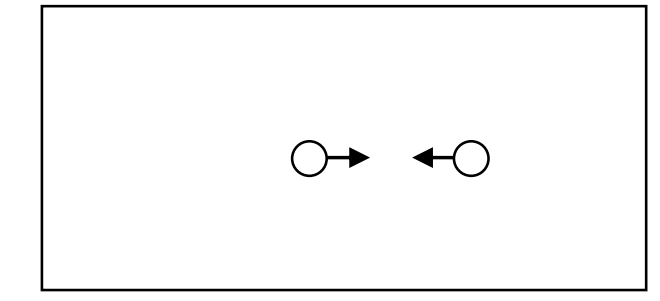

Gambar 31. Pola lantai awal penari Lukah Gilo (saling berhadapan memegang lukah yang akan dimantrai)

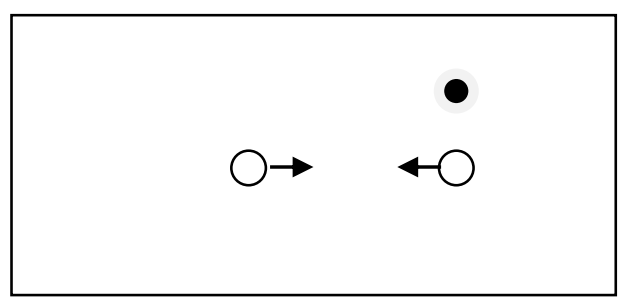

Gambar 32. Pola lantai lanjutan ( kulipah membisikkan mantera ke lukah)

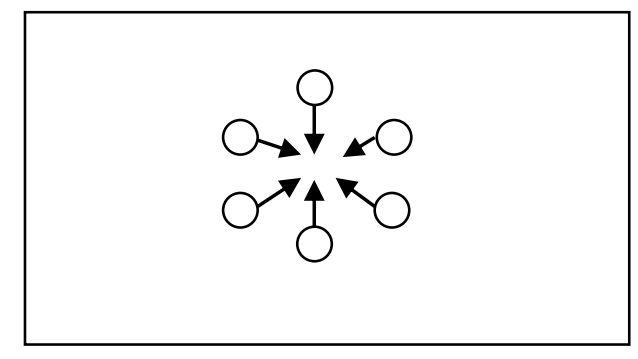

Gambar 33. Pola lantai lingkaran

Keterangan:

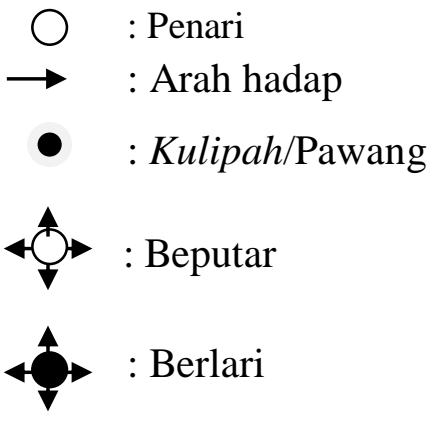

\section{H. Pelaku Pertunjukan}

Tari Lukah Gilo termasuk dalam jenis tari kelompok. Tari Lukah Gilo ditarikan oleh penari laki-laki, dengan semua 
pendukung tarinya berjenis kelamin laki-laki semua, hal ini dikarenakan hanya kaum lakilaki yang dianggap mampu melaksanakan tari Lukah Gilo.

Jumlah penari pada tari Lukah Gilo dapat dibedakan sesuai dengan acaranya, apabila diadakan untuk upacara adat, maka penari berjumlah dua atau tiga orang dan satu kulipah. Jika untuk pertunjukan seni atau hiburan, penari berjumlah dua atau lima orang atau lebih dan satu kulipah. Pada pertunjukan tari Lukah Gilo di masyarakat Sijunjung, lukah gilo hanya difokuskan untuk hiburan semata, yang terdiri dari 2 (dua) penari silat, 6 (enam) penari Lukah Gilo, dan 1 (satu) orang kulipah.

\section{Waktu Pertunjukan}

Tari Lukah Gilo yang identik dengan kekuatan magis berpengaruh pula pada waktu pelaksanaannya. Biasanya kesenian ini dipentaskan pada malam hari. Menurut kulipah, waktu malam hari dianggap tepat untuk memanggil jin yang akan dimasukkan ke dalam lukah. Waktu malam hari ini pula yang menyebabkan pertunjukan tari Lukah Gilo ini terasa semakin magis. Pada perkembangannya, pertunjukan tari Lukah Gilo tidak hanya dapat dipentaskan pada malam hari, namun juga dapat dipentaskan pada pagi, siang, atau sore hari. Hal tersebut tergantung pada acara dan keinginan yang memiliki hajat.

Pada pertunjukan yang diamati, tari Lukah Gilo dilaksanakan pada malam hari tepatnya setelah shalat Isya. Sebelum pertunjukan berlangsung, warga setempat yang telah mengetahui akan diadakannya pertunjukan Lukah Gilo berbondong-bondong datang ke tempat pertunjukan dengan tujuan menonton pertunjukan tersebut.

\section{J. Properti}

Properti yang digunakan dalam tari Lukah Gilo yaitu lukah (bubu). Bubu merupakan alat alat penangkap ikan atau belut berbentuk lonjong yang terbuat dari dari anyaman lidi atau rotan. Penggunaan properti lukah untuk pertunjukan tari Lukah Gilo di Sijunjung divisualisasikan seperti boneka. Pemakaian kostum yang menyerupai perempuan dimaksudkan agar lukah terlihat menarik dan menjadi primadona pada pertunjukannya. Tidak hanya itu, visualisasi sosok perempuan juga bertujuan agar jin yang dimasukkan ke dalam lukah akan memberontak karena tidak sesuai dengan jati diri jin tersebut, karena jin yang dimasukkan ke dalam lukah umumnya berjenis kelamin laki-laki.

Penggunaan properti lukah pada tari Lukah Gilo sangat penting dan menjadi media utama dalam pertunjukan lukah gilo. Hal ini dikarenakan pertunjukan tari Lukah Gilo yang merupakan gerak keseluruhan yang dilakukan oleh penari atau pemegang lukah merupakan gerak responsif atau gerak spontan dari gerakan lukah yang telah dibacakan mantera.

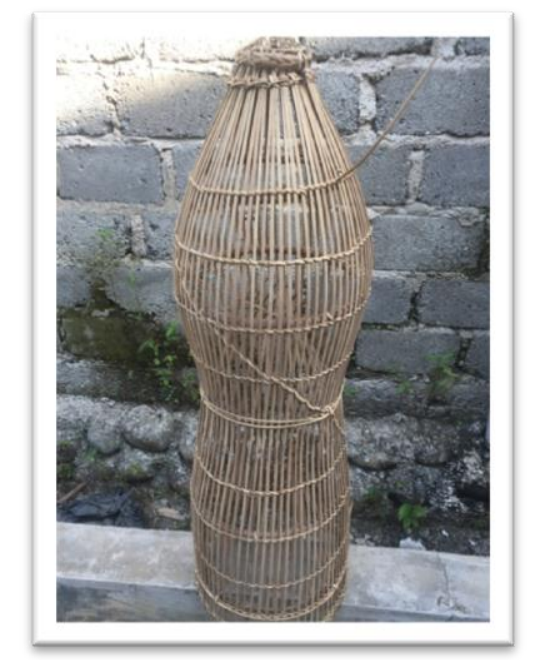

Gambar 12. Foto lukah sebagai media utama tari Lukah Gilo 
(Dokumentasi: Tommi, 30 April 2018).

\section{PENUTUP}

Tari Lukah Gilo merupakan salah satu kesenian yang hidup dan berkembang di Sijunjung, Sumatera Barat yang sarat dengan kekuatan supranatural dan unsur magis. Dilakukan oleh beberapa orang laki-laki yang berperan sebagai penari dan seorang kulipah (pawang), tari ini menggunakan lukah (bubu) sebagai properti utamanya. Keunikan pada tarian ini terletak pada properti lukah yang dapat bergerak sendiri seolah menari-nari, setelah dibacakan mantera oleh kulipah, sehingga lukah tersebut akan melompat dan juga menari tanpa digerakkan oleh seseorang. Pada dasarnya, tarian ini berupa kontrol atau pengendalian lukah (bubu) oleh para penari yang akan berusaha membuat lukah tetap berdiri tegak.

Terbentuknya kesenian Lukah Gilo diyakini berlatar belakang situasi dan kondisi kehidupan masyarakat Sujunjung, yaitu terinspirasi dari cerita Duhak, seorang warga Sijunjung yang gemar mencari ikan di sungai dengan menggunakan alat penangkap ikan berupa lukah (bubu). Namun karena kesombongannya, salah seorang warga memanterai lukahnya agar ikan tangkapannya tumpah. Melihat lukah yang dimanterai tersebut dapat bergerak sendiri tanpa digerakkan lalu munculah ide untuk membuat kesenian dengan menggunakan lukah.

Dari penyajiannya, tari Lukah Gilo di Sijunjung terbagi menjadi tiga tahapan penyajian, yaitu tahap persiapan, tahap pelaksanaan, dan tahap penutup. Tahap persiapan merupakan tahap di mana segala kebutuhan pertunjukan akan disiapkan, mulai dari mempersiapkan lukah, dan menghias lukah menyerupai boneka. Tahap pelaksanaan atau pementasan dipimpin oleh kulipah dengan menghadirkan jin untuk meng-gilo-kan lukah, dan tahap penutup yang merupakan akhir dari pertunjukan tari Lukah Gilo. Pada tahapan ini tidak semua jin yang masuk ke dalam lukah akan dikeluarkan oleh kulipah. Jin dapat pergi sendiri ketika penari merasakan lelah dan melepaskan yang kemudian lukah akan terjatuh ke tanah.

Tari Lukah Gilo di Sijunjung dikemas dengan sederhana dan sebagai sarana hiburan tanpa meninggalkan unsur magis di dalamnya. Pertunjukan tari Lukah Gilo di Sijunjung tidak menggunakan sesaji sebagai media untuk memanggil jin yang akan dimasukkan ke dalam lukah. Tari Lukah Gilo yang tumbuh dan berkembang di Sijunjung telah mengalami banyak perubahan serta perkembangan sesuai dengan kondisi dan keadaan masyarakat Sijunjung. Perubahan dan perkembangan itu tampak pada bentuk penyajiannya, tampak pada penggunaan kostum dan instrumen iringannya. Busana yang dikenakan merupakan busana khas Minangkabau, yaitu baju taluak balango (kemeja longgar berwarna hitam), salempang atau selendang, serawa (celana) berwarna hitam, sisampiang (sarung setengah lutut), dan bagian kepala memakai deta batik. Instrumen musik yang mengiringinya terdiri dari enam pencu talempong dan satu buah kendang, vokal dari kulipah dan suara tepuk tangan dan suara dari tepukan celana galembong. Tempat pementasannya adalah di halaman atau di lapangan. Waktu pementasannya pada malam hari tepatnya setelah shalat isya. Dari penjabaran bentuk penyajian secara keseluruhan unsur-unsur pementasan merupakan sebuah kesatuan tata gerak, tata iringan, tata pentas, tata rias dan busana yang tidak dapat dipisah-pisahkan. 
Dapat ditarik kesimpulan bahwa tari Lukah Gilo merupakan kesenian tradisional yang syarat dengan kekuatan magis yang pada masa sekarang berfungsi sebagai sarana seni tontonan atau hiburan. Tari Lukah Gilo tetap tumbuh dan dilestarikan karena berada pada undang-undang adat yang mengatur tentang seni dalam masyarakat Minangkabau dan tidak bertentangan dengan falsafah adat Minangkabau "Adat basandi syarak, syarak basandi kitabullah" dan erat hubungannya dengan adat nan diadatkan sebagai kesenian warisan nenek moyang serta adat istiadat yang dapat berubah dan berkembang sesuai dengan kebutuhannya. Berdasarkan topik penelitian yang mengangkat bentuk penyajian, maka tari Lukah Gilo di masyarakat Sijunjung berbeda dengan yang ada di daerah lain. Perbedaan ini menjadi ciri khas pada pertunjukan tari Lukah Gilo yang ada di Sijunjung.

\section{DAFTAR SUMBER ACUAN}

\section{A. Sumber Tertulis}

Desfiarni. 2014. Tari Lukah Gilo: Sebagai Rekaman Budaya Minangkabau Pra Islam dari Magis ke Seni Pertunjukan Sekuler. Yogyakarta: Kalika.

Hamka. 1984. Islam dan Adat Minangkabau. Jakarta: Pustaka Panji Mas.

Koto, Tsuyoshi. 1983. Matriliny and Migrations. Terjemahan Azizah Kasim. Nasab Ibu dan Merantau. Kuala Lumpur: Dewan Bahasa dan Pustaka.
Manners, Albert A dan David Kaplan. 1999. Teori Budaya. Yogyakarta: Pustaka Pelajar.

Murgiyanto, Sal. 1977. Pedoman Dasar Mencipta Tari. Jakarta: Lembaga Pendidikan Kesenian Jakarta.

Naim, Muhtar. 1984. Marantau Pola Migrasi Suku Minangkabau. Yogyakarta: Gadjah Mada University Press.

Smith, Jacqueline. 1985. Dance Composition: A Practical Guide for Teachers terjemahan Ben Suharto Komposisi Tari: Sebuah Petunjuk Praktis Bagi Guru. Yogyakarta: Ikalasti.

Soedarsono, R.M, 1997, Tari-tarian Indonesia I, Jakarta: Proyek Pengembangan Media

Kebudayaan Direktorat Jendral Kebudayaan Department Pendidikan dan Kebudayaan.

\section{B. Narasumber}

Buya Herdian Fauzi, 35th, kulipah tari Lukah Gilo dan pimpinan sanggar Sarunai Sangkokalo di Sijunjung, Sumatera Barat. 